\title{
Hydroponic Culturing Upregulates Sucrose and Glutamine Metabolism by Enhancing Their Utilization via Intermediates of Aerobic Pathway in Wheat
}

\author{
B. KAUR and B. ASTHIR* \\ Department of Biochemistry, Punjab Agricultural University, Ludhiana-141004, Punjab, India \\ (Received 9 July 2015; Accepted 27 October 2015; \\ Communicated by J. Zhang)
}

\begin{abstract}
Two wheat genotypes were grown in hydroponic culture, containing $4 \mathrm{mM} \mathrm{KNO}_{3}, \mathrm{NH}_{4} \mathrm{Cl}$ and $\mathrm{NH}_{4} \mathrm{NO}_{3}$. Activities of $\mathrm{N}$ metabolizing enzymes, aminotransferases, carbohydrate and TCA cycle enzymes were analyzed along with protein, amino acid, N, sugar content and growth parameters in shoot and root. After 12 days, the size of shoot and root system decreased significantly when plants were supplied with $\mathrm{NH}_{4} \mathrm{Cl}$ as exclusive $\mathrm{N}$ source. Under $\mathrm{NH}_{4} \mathrm{NO}_{3}$ growth parameters, $\mathrm{N}$ and carbon metabolism were elevated as compared to $\mathrm{NH}_{4} \mathrm{Cl}$ but less than $\mathrm{KNO}_{3}$ source indicating inhibition of $\mathrm{NH}_{4}{ }^{+}$toxicity by $\mathrm{NO}_{3}{ }^{-}$uptake. Our results suggested that GDH, aminotransferases and PEPC play an important role in ammonium detoxification by its incorporation into amino acids. Thus, the morphologic differences among plants growing in $\mathrm{NH}_{4}{ }^{+}$or $\mathrm{NO}_{3}{ }^{-}$nutrition confirm the hypothesis that $\mathrm{N}$ source determines the growth habit of plant in wheat by modulating the endogenous levels of protein and sugar content.
\end{abstract}

Keywords: nitrogen, carbon, hydroponics, wheat, genotypes

Abbreviations: 2-OG: 2-oxoglutarate, GDH: glutamate dehydrogenase, GOGAT: glutamate synthase, GOT: glutamate oxaloacetate transaminase, GPT: glutamate pyruvate transaminase, GS: glutamine synthetase, ICDH: isocitrate dehydrogenase, $\mathrm{MDH}$ : malate dehydrogenase, NR: nitrate reductase, PEPC: phosphoenolpyruvate carboxylase.

\section{Introduction}

Plant may take up nitrogen in various forms, the main sources are nitrate and ammonium ions (Bijlsma et al. 2000; Rad et al. 2013). The physiological responses of plants to these ions are very different and the ability of plants to absorb and metabolize them varies greatly (Cossey et al. 2002). Nitrogen assimilation takes place both in leaves and in roots (Masclaux-Daubresse et al. 2010). The distribution of nitrogen assimilation throughout the plants depends on the plant species, age and environmental factors (Wojciechowski et al. 2009; Bai et al. 2013). Ammonium originates in the plant from nitrate reduction by nitrate reductase, direct absorption, photorespiration, or deamination of nitrogenous com- 
pounds; it is assimilated into organic molecules primarily by the combined catalytic action of two enzymes, glutamine synthetase and glutamate synthase (Masclaux-Daubresse et al. 2006; Morozkina and Zvyagilskaya 2007). Glutamate oxaloacetate transaminase and glutamate pyruvate transaminase are responsible for the biosynthesis of glutamine to other amino acids, forming storage protein molecule and thus play an important role in regulation of nitrogen metabolism in crop plants (Lea et al. 1990). Glutamate dehydrogenase catalyzes the amination of 2 oxoglutarate and the deamination of glutamate; the direction of the activity depends on specific environmental conditions (Tercé-Laforgue et al. 2004; Osuji et al. 2009).

Sucrose, the major translocate form of carbon from source to sink tissue and is degraded by sucrose synthase, acid invertase and neutral invertase (Jiang et al. 2003). However, carbon and nitrogen assimilation requires a substantial contribution of fixed carbon in both leaves and roots. In leaves, triose-P enters the glycolytic pathway directly. In roots, carbon is required directly as $\alpha$-ketoglutarate (by metabolism of sucrose through glycolysis/Krebs) and indirectly by the generation of reducing power (reduced Fd) in the plastids. Phosphoenolpyruvate derived from glucose reacts with carbon dioxide from the atmosphere to yield oxalacetic acid through phosphoenolpyruvate carboxylase (PEPC). Therefore, PEPC may be an important interface between carbon and nitrogen metabolism (Miyao and Fukayama 2003). Isocitrate dehydrogenase catalyzes the reversible conversion of isocitrate to 2-oxoglutarate (2-OG) and links carbon and nitrogen metabolism (Lancien et al. 2000; Nunes-Nesi et al. 2010). Malate dehydrogenase catalyzes the interconversion of oxaloacetate and malate and exists in different isoforms (Gietl 1992).

In this paper, we study the response of hydroponically grown two wheat genotypes, PBW 343 and GLU 1356, to different nitrogen source on nitrogen and carbon metabolism. These species were chosen because they differ in their nitrogen use efficiency; PBW 343 (low yield) and GLU 1356 (high yield). Therefore, the aim of this paper is to analyze the differences of these genotypes in different forms of nitrogen assimilation which could help to elucidate the mechanism of ammonium nutrition tolerance.

\section{Materials and Methods}

Two wheat genotypes (PBW 343 and GLU 1356) were grown hydroponically in a greenhouse in plastic trays containing 8 L Hoagland solution during 2013 and 2014. Table 1 summaries the important features of two wheat genotypes used for biochemical analysis at different nitrogen sources. Seed from each genotype were sprouted in a controlled en-

Table 1. Important features of two wheat genotypes used for study

\begin{tabular}{|c|c|c|}
\hline Genotype & Parentage & Important features \\
\hline PBW 343 & ND/VG9144//KAL/BB/3/YACO'S'/4/Vec\#5 & $\begin{array}{l}\text { Widely sown released variety for timely sown } \\
\text { irrigated conditions }\end{array}$ \\
\hline GLU 1356 & GLUPRO/3*PBW554(BWL 0975) & $\begin{array}{l}\text { Lines with high grain protein content conferred } \\
\text { by } G p c-B 1 \text { gene originally introgressed from } \\
\text { Triticum dicoccoides (Tetraploid wild wheat) }\end{array}$ \\
\hline
\end{tabular}


vironment in paper towels. After the seeds germinated, the seedlings were transferred to trays in the greenhouse. Each tray contained one genotype at one nitrogen rate. The trays contained Hoagland solution (Hoagland and Arnon 1950) that supplied with (a) $\mathrm{C}-$ control (Hoagland solution), (b) $4 \mathrm{mM} \mathrm{KNO}_{3}$, (c) $4 \mathrm{mM} \mathrm{NH}_{4} \mathrm{Cl}$ and (d) $4 \mathrm{mM} \mathrm{NH}_{4} \mathrm{NO}_{3}$. The solutions were aerated continuously through the use of an air compressor. The $\mathrm{pH}$ of the solution was monitored daily and maintained at 6.0-6.5 with either $1 \mathrm{~N} \mathrm{HCl}$ or $1 \mathrm{~N} \mathrm{NaOH}$ to prevent any iron deficiency symptoms. Solution was replaced after every 3 days. Plants were harvested at 12 days after transfer to the greenhouse. The plants were separated into shoots and roots and analyzed for various parameters.

\section{Plant growth parameters}

In separate experiment, plant parts were separated into root and shoot. Their length and fresh weight of wheat plants (12 individual plants per treatment from five hydroponic trays) were determined.

\section{Enzyme assays}

Nitrate reductase, glutamine synthatase, glutamate synthase, glutamate dehydrogenase, glutamate oxaloacetate transaminase and glutamate pyruvate transaminase

The nitrate reductase activity was estimated by the method described by Jaworski (1971). Glutamine synthatase (GS), glutamate synthase (GOGAT) and glutamate dehydrogenase (GDH) activity were extracted by the method of Mohanty and Fletcher (1980). The GS activity was assayed by Kanamori and Matsumoto (1974). The activity of GOGAT and GDH was assayed by the method describes by Bulen (1956). Glutamate oxaloacetate transaminase (GOT) and glutamate pyruvate transaminase (GPT) was determined following the procedure of Tonhazy $(1960 \mathrm{a}, \mathrm{b})$. The procedure for assaying GPT activity was same as described for GOT except that the addition of aniline citrate step was omitted.

\section{Sucrose synthase, soluble acid invertase and soluble neutral invertase}

Enzymes were extracted from fresh tissue samples essentially by the method Stommel (1992) and the activity of sucrose synthase (UDPglucose-fructose-2- $\alpha$-D glucosyltransferase) assayed by the method Morell and Copeland (1985). The soluble acid invertase $(\mathrm{pH} 4.8)$ and soluble neutral invertase $(\mathrm{pH} 7.5)$ ( $\beta$-D-fructofuranoside fructohydrolase) activities were assayed essentially by the method described previously by Singh and Asthir (1988).

\section{Phosphoenolpyruvate carboxylase, isocitrate dehydrogenase and malate dehydrogenase}

Extraction: Fresh tissue $(100 \mathrm{mg})$ were homogenized in a pre-chilled pestle with $2 \mathrm{ml}$ of $50 \mathrm{mM}$ Tris- $\mathrm{HCl}$ buffer $(\mathrm{pH}$ 7.6). The homogenate was centrifuged at $10,000 \times \mathrm{g}$ for 20 min and the clear supernatant was used for the enzyme assay. 
Phosphoenolpyruvate carboxylase activity was measured by the method described by Christeller et al. (1977). Isocitrate dehydrogenase activity was assayed by the procedure given by Tezuka et al. (1990). Malate dehydrogenase was determined following the procedure optimized from Vance and Stade (1984).

\section{Extraction and estimation of various metabolites}

\section{Total free sugars}

Free sugars were extracted sequentially with $80 \%$ and $70 \%$ ethanol. The extracts containing sugars were concentrated by evaporating off the ethanol under vacuum. The total free sugars were determined colorimetrically using the reaction with phenol (Dubois et al. 1956).

\section{Protein, amino acid and nitrogen content}

Proteins were extracted in $0.1 \mathrm{M} \mathrm{NaOH}$ and precipitated with trichloroacetic acid (TCA) and estimated by the method of Lowry et al. (1951). The amino acid was estimated by method described by Lee and Takahashi (1966) and nitrogen content was estimated by the method given by McKenzie and Wallace (1954).

\section{Statistical analysis}

All the values were mean of three replicates. Data obtained was subjected to CRD at 5\% level of CD using CPCS1 software developed by the Department of Statistics, Punjab Agricultural University, Ludhiana, India.

\section{Results}

Tissue culture technique is an alternative way of studying the hypothesis that different nitrogen nutrition determines the growth habit of wheat by modulating nitrogen and carbon metabolism. In this study, the response of hydroponically grown two wheat genotypes (PBW 343 and GLU 1356) at different nitrogen source $\left(\mathrm{C}\right.$ - control, $4 \mathrm{mM} \mathrm{KNO}_{3}$, $4 \mathrm{mM} \mathrm{NH}_{4} \mathrm{Cl}$ and $4 \mathrm{mM} \mathrm{NH}_{4} \mathrm{NO}_{3}$ ) were studied. The results of enzymatic and metabolites analysis (protein, amino acid, nitrogen and sugars) in shoot and root of two wheat genotypes under different nitrogen sources are summarized in Figs S1*, S2 and S3; Table S1 and the correlation between various parameters is given in Table S2.

\section{Growth parameters}

The present study showed that plant growth parameters, viz. root-shoot length and biomass were reduced with $\mathrm{NH}_{4} \mathrm{Cl}$ nutrition as compared to $\mathrm{NH}_{4} \mathrm{NO}_{3}$ and $\mathrm{KNO}_{3}$ fed plants 
(Table S1). The increase in shoot length as well as biomass were higher in GLU 1356 as compared to PBW 343.

\section{Enzyme activities}

The result indicated that, there were differences in the contribution of nitrogen metabolizing, viz. nitrate reductase (NR), glutamine synthetase (GS), glutamate synthase (GOGAT), glutamate dehydrogenase (GDH); aminotransferases, viz. glutamate oxaloacetate transaminase (GOT), glutamate pyruvate transaminase (GPT); sucrose metabolizing, viz. sucrose synthase (SS), soluble acid invertase (AI), soluble neutral invertase (NI) and TCA cycle enzymes, viz. phosphoenolpyruvate carboxylase (PEPC), isocitrate dehydrogenase $(\mathrm{ICDH})$, malate dehydrogenase $(\mathrm{MDH})$ depending on the species, nitrogen nutrition and plant organ (Figs S1 and S2). In short, nitrogen source upregulates the activities of these enzymes but it varies depending on different types of nitrogen sources.

Our results showed that $\mathrm{KNO}_{3}$ and $\mathrm{NH}_{4} \mathrm{NO}_{3}$ source significantly increased the activities of NR, GS, GOGAT, GOT and GPT in shoot as compared to $\mathrm{NH}_{4} \mathrm{Cl}$ conditions. Whereas, application of $\mathrm{NH}_{4} \mathrm{Cl}$ results in increase in activities of GS-GOGAT and aminotransferases (GOT and GPT) in shoot as well as in root but significant increase was observed in GDH activity.

On the other hand, with $\mathrm{KNO}_{3}$ and $\mathrm{NH}_{4} \mathrm{NO}_{3}$ source, the slight increase in activity of SS was recorded, whereas AI and NI showed significant increase as compared to $\mathrm{NH}_{4} \mathrm{Cl}$ in shoot. However in roots, $\mathrm{AI}$ and NI activities was significantly upregulated by $\mathrm{NH}_{4} \mathrm{Cl}$.

Activities of TCA cycle enzymes such as PEPC, ICDH and MDH were also measured and the results are shown in Fig. S2. The supply of carbon skeletons from phosphoenolpyruvate for ammonium assimilation can be met by PEPC enzyme. The activity of this enzyme changed when ammonium was the nitrogen source as compared to nitrate. Furthermore, the activities of PEPC and malate dehydrogenase (MDH) increased when $\mathrm{NH}_{4} \mathrm{Cl}$ was used as nitrogen source as compared to $\mathrm{KNO}_{3}$ and $\mathrm{NH}_{4} \mathrm{NO}_{3}$ only in roots whereas isocitrate dehydrogenase (ICDH) do not show significant difference with respect to different nitrogen nutrition in both shoot and root. In contrast, MDH activity increased with $\mathrm{NH}_{4} \mathrm{Cl}$ and the PEPC activity increased with $\mathrm{KNO}_{3}$ and $\mathrm{NH}_{4} \mathrm{NO}_{3}$ in shoot.

\section{Metabolite analysis}

The effect of $\mathrm{KNO}_{3}$ and $\mathrm{NH}_{4} \mathrm{NO}_{3}$ as nitrogen source significantly increased total protein content, amino acid and nitrogen content in shoot as compared to $\mathrm{NH}_{4} \mathrm{Cl}$ source (Fig. S3). Whereas in root, $\mathrm{NH}_{4} \mathrm{Cl}$ significantly increases the soluble protein content and amino acid, in contrast with $\mathrm{KNO}_{3}$ and $\mathrm{NH}_{4} \mathrm{NO}_{3}$ increases nitrogen content. However, total sugars significantly decreased with nitrogen treatment. On comparison between shoot and root, soluble protein, nitrogen and sugar content were more in shoot whereas amino acid content was in root.

In general, a different trend was observed depending on the species. The increase in activity of all the enzymes and various metabolites were more in GLU 1356 than PBW 343. 
A significant correlation of NR, GS, GOGAT, GOT, GPT, AI, NI, ICDH and MDH with protein content $r=0.94,0.96,0.91,0.91,0.81,0.83,0.87,0.71$ and 0.84 , respectively $(\mathrm{p}<0.01)$, was observed in shoot whereas in root, GOGAT, GDH, GPT, AI, NI, PEPC and MDH correlated $r=0.77,0.88,0.75,0.87,0.89,0.97$ and 0.94 , respectively (Table S2). On the other hand, amino acid showed significant correlation with GS, GOGAT, GOT, GPT and AI ( $\mathrm{r}=0.73,0.78,0.80,0.75$ and 0.82 , respectively, in shoot, in root it positively correlated with GS, GPT and ICDH; $r=0.95,0.78$ and 0.93 , respectively. Instead of these, nitrogen also significantly correlated with GS, GOGAT, GOT, GPT, AI, NI and PEPC in shoot $(\mathrm{r}=0.79,0.95,0.93,0.98,0.99,0.77$ and 0.79 , respectively), in root with GS, GPT and ICDH ( $\mathrm{r}=0.77,0.75$ and 0.87 , respectively). Whereas total protein, amino acid, nitrogen content were non-significantly correlated with total free sugar content in shoot $(\mathrm{r}=0.48,0.47$ and 0.11 , respectively) and negatively correlated in root, $\mathrm{r}=-0.19,-0.25$ and -0.48 , respectively $(\mathrm{p}<0.01)$.

\section{Discussion}

In soils there is competition between plants and other organisms in the rhizosphere for available nitrogen. Plants can cope with limited supply and competition by opportunistically utilizing other forms of nitrogen in the rhizosphere (e.g., amino acids) to replace or supplement soil nitrate and ammonium (Nasholm et al. 2009). Moreover, studies conducted in the past highlighted the response of various nitrogen fertilizer supplied in soil which caused tremendous losses of nitrogen to the atmosphere due to denitrification and leaching (Luo et al. 2006; Anjana et al. 2007). However, hydroponically grown seedlings not only showed positive response of the direct uptake of nitrogen by seedlings but also provided additional support on the possible contribution of different nitrogen sources using direct tissue culturing technique towards nitrogen and carbon metabolism.

According to results, growth parameters increased with $\mathrm{NH}_{4} \mathrm{NO}_{3}$ treatment as compared to $\mathrm{NH}_{4} \mathrm{Cl}$ supply, indicated that ammonium uptake inhibited by nitrate in tissue culture and reduces the carbon stress in the roots of nitrate plus ammonium fed wheat plants occasioned by the assimilation and subsequent translocation of nitrogen to the shoot. Thus, more carbon is available for the extension of the root in mixed nitrogensource fed plants in comparison with ammonium-only fed plants, allowing normal root development and exhibit superior growth rate and productivity. PBW 343 was highly sensitive to ammonium nutrition resulted in reduced shoot growth as compared to GLU 1356 which consider as ammonium tolerance.

Our results showed that $\mathrm{KNO}_{3}$ source significantly increased the activities of nitrogen metabolizing enzymes and aminotransferases as also reported by Jain et al. (2011); Anjana et al. (2011); Asthir and Bhatia (2014); Hawkesford (2014). Whereas, $\mathrm{NH}_{4} \mathrm{Cl}$ elevated activities of GS-GOGAT and aminotransferases (GOT and GPT) along with increase in acid and neutral invertase activities in shoot as well as in root which indicated that unregulated uptake of ammonium supplied as a single nitrogen source is considered to exert a carbon stress on plant roots for its assimilation and subsequent translocation to shoots (Lewis et al. 1987; Britto and Kronzucker 2002). Ammonium increased GS activ- 
ity both in shoots as in roots and GDH activity mainly in roots and slightly in shoots. Thus, GS activity was localized mainly in the shoots, whereas that of GDH was in the roots. Even though the GS/GOGAT pathway is the major route in higher plants (Miflin and Lea 1976), they are able to use other alternative routes such as those catalyzed by $\mathrm{GDH}$, which catalyzes the reversible amination of 2 oxoglutarate to yield glutamate. Results of present experiment have shown that GDH activity increased in wheat seedlings when switched from nitrate to ammonium and this increase was correlated with an increase in the amino acid content, showing that the aminating activity of GDH may have a role in the ammonium detoxification. In this case, GDH activity was higher in ammonium-fed plants compared to nitrate-fed plants in both the species. However, $\mathrm{NH}_{4} \mathrm{NO}_{3}$ increased the activities of NR, GS, GOGAT, GOT and GPT in shoot and decreased the activities of GS, GOGAT, GOT and GPT in roots indicating shoots are better in nitrate assimilation. This study deduce that NR plays an important role in the absorption of $\mathrm{NO}_{3}^{-}$, regulating the levels of $\mathrm{NO}_{3}{ }^{-}$and amino acids in root cells. Since $\mathrm{NO}_{3}{ }^{-}$induces NR activity, therefore enhanced rate of $\mathrm{NO}_{3}{ }^{-}$uptake to the site of induction is the main controlling factor for the level of $\mathrm{NR}$ activity (Balotf et al. 2012). As $\mathrm{NH}_{4} \mathrm{NO}_{3}$ increases the activity of nitrogen metabolizing and aminotransferases enzymes, we therefore speculate that high concentrations of ammonium nitrogen in nutrient solution may lead to accumulation of toxic amounts of ammonium ions in the plants (Britto and Kronzucker 2002; Lasa et al. 2002). Similar to our observation, Lewis et al. (1987), Britto and Kronzucker (2002) and Cruz et al. (2006) proposed that, the presence of nitrate in the nutrient medium suppresses an over-rapid absorption of the ammonium ion and the consequent over-allocation of carbon to nitrogenous compounds, most of which are transported out of the root to the shoot.

The increase in protein content was in parallel with activities of GOT and GPT as also reported by Asthir and Bhatia (2014). It seems that through enhancement of the activity of transaminases, results in accumulation of high level of exogenously-supplied nitrogen and its transformation to proteins. But increase in amino acid in $\mathrm{NH}_{4} \mathrm{Cl}$ treated plants results in decrease of protein content which lead us to suggest that hydrolysis of proteins might be responsible for the accumulation of amino acids in wheat as also observed by Lin and Kao (2001) in rice leaves. Apparently, there is a glutamine-mediated diversion of sucrose and starch towards protein synthesis as observed earlier in rice grains (Singh et al. 1978). Since conversion of glutamine to glutamate by GOGAT in seeds needs 2-oxoglutarate which is derived from sucrose catabolism, therefore the higher concentration of glutamine causes greater generation of this organic acid (Hodges 2002; Lancien et al. 2002).

In our experiments $\mathrm{NH}_{4} \mathrm{Cl}$ supply caused a significant increase in amino acids content as compared with $\mathrm{KNO}_{3}$ and $\mathrm{NH}_{4} \mathrm{NO}_{3}$ plants which is consistent with the results of Pasqualini et al. (2001); Patterson et al. (2010) who proposed that $\mathrm{NH}_{4}{ }^{+}$ion diverted the assimilated carbon mainly towards amino acids. As $\mathrm{KNO}_{3}$ and $\mathrm{NH}_{4} \mathrm{NO}_{3}$ nitrogen source resulted in higher nitrogen content, which can be correlated with higher activities of nitrogen metabolizing as well as aminotransferases enzymes as also reported by Below et al. (2000). Plants treated with $\mathrm{NH}_{4} \mathrm{Cl}$, as exclusive nitrogen source, showed lower level of 
total sugars than those treated with $\mathrm{NO}_{3}{ }^{-}$. The rapid assimilation of $\mathrm{NH}_{4}{ }^{+}$in glutamine led to a consumption of carbon skeletons, causing depletion of the foliar starch and sucrose (Ikram et al. 2012; Schluter et al. 2012), likewise Britto and Kronzucker (2002) concluded that the consumption of fixed carbon during the assimilation of $\mathrm{NH}_{4}{ }^{+}$could appreciably reduce sugars results in increases amino acids.

The metabolic pathways of nitrogen and carbon are linked since nitrogen assimilation requires carbohydrates for the production of energy and the provision of carbon skeletons. As results indicated $\mathrm{KNO}_{3}$ plants had higher activities of sucrose synthase than $\mathrm{NH}_{4} \mathrm{Cl}$ plants, in the latter system the activity of acid invertase doubled that of $\mathrm{KNO}_{3}$ plants, so speeding up sugars breakdown and, as a consequence, there are more carbon chains to form amino acids and for $\mathrm{NH}_{4}{ }^{+}$assimilation as also reported by Raab and Terry (1994); Britto and Kronzucker (2002). Besides, while nitrate can be accumulated in vacuoles, ammonium ions are toxic and need to be rapidly assimilated. In this experiment, we verified that the activity of the enzymes implicated in the TCA cycle, such as MDH, PDC and $\mathrm{ICDH}$, is stimulated under ammonium nutrition in both species, and this result highly correlates to organic acid content (Lasa et al. 2002). The stimulation of the activities of PEPC and $\mathrm{MDH}$ when $\mathrm{NH}_{4} \mathrm{NO}_{3}$ and $\mathrm{NH}_{4} \mathrm{Cl}$ used as nitrogen sourse occur in roots whereas in shoot $\mathrm{ICDH}$ and $\mathrm{MDH}$ activity stimulated with $\mathrm{NH}_{4} \mathrm{NO}_{3}$ and $\mathrm{NH}_{4} \mathrm{Cl}$ sources. The stimulation of these enzymes at different level in shoots and roots of wheat seedling, indicating once again that these species assimilate ammonium in different organs. The stimulation of respiration that occurs in vascular plants during nitrogen uptake has been ascribed to an initial activation PEPC leading to an increased production of citric acid cycle carbon skeletons needed for ammonium assimilation (Huppe and Turpin 1994). Our results also show that ammonium nutrition stimulates PEPC activity. However, there was a difference in behavior depending on the species. Therefore, according to results, it can be concluded that ammonium assimilation requires availability of carbon skeletons that increase the TCA cycle carbon flow (Miyao and Fukayama 2003; Lasa 2002; Hodges 2002; Roosta et al. 2009). Since the carbon skeletons are replenished via anaplerotic dark carbon fixation, it is conceivable that in vivo PEPC activity and/or the provision of the substrate for the dark carbon fixation in roots may be responsible for the regulation in the replenishment of carbon skeletons. The root is a specific site for ammonium assimilation in plants (Miyao and Fukayama 2003).

Results showed that high activities of nitrogen and carbon metabolizing enzymes in GLU 1356 resulted in high nitrogen uptake and contents of soluble protein, amino acid and nitrogen as compared to PBW 343. Genotypic variation exists for the rate of nitrogen uptake, its accumulation, assimilation and translocation in different tissues as also reported by Sadras and Lawson (2013); Fathi (2008).

In this report, we have demonstrated the considerable inhibition of ammonium uptake by nitrate in hydroponic culture, which proposed that inhibition reduces the carbon stress in the root of $\mathrm{NH}_{4} \mathrm{NO}_{3}$ fed wheat plants occasioned by the assimilation and subsequent translocation of nitrogen to the shoot. Thus, more carbon is available for the extension of the root in $\mathrm{NH}_{4} \mathrm{NO}_{3}$ fed plants in comparison with the $\mathrm{NH}_{4} \mathrm{Cl}$ fed plants. However, $\mathrm{NH}_{4} \mathrm{Cl}$ fed plants significantly enhances the activities of TCA cycle enzymes which provides the 
carbon skeleton for ammonium assimilation reduces its toxicity effect whereas $\mathrm{KNO}_{3}$ fed plants upregulated the nitrogen metabolizing enzymes which increases the nitrogen uptake. Therefore, these findings could be utilized for further study on nitrogen and carbon metabolism in plants. Moreover, our results highlight the importance of the GDH and PEPC as enzymes more efficient for ammonium detoxification.

\section{Conflict of Interest}

The authors declare that they have no conflict of interest.

\section{References}

Anjana, S.U., Iqbal, M., Abrol, Y.P. 2007. Are nitrate concentrations in leafy vegetables within safe limits? Current Sci. 92:355-360.

Anjana, S.U., Abrol, Y.P., Iqbal, M. 2011. Modulation of nitrogen utilization efficiency in wheat genotypes differing in nitrate reductase activity. J. Plant Nutr. 34:920-933.

Asthir, B., Bhatia, S. 2014. In vivo studies on artificial induction of thermotolerance to detached panicles of wheat (Triticum aestivum L.) cultivars under heat stress. J. Food Sci. and Technol. 51:118-123.

Bai, C.H., Liang, Y.L., Hawkesford, M.J. 2013. Identification of QTLs associated with seedling root traits and their correlation with plant height in wheat. J. Exp. Bot. 64:1745-1753.

Balotf, S., Niazi, A., Kavoosi, G., Ramezani, A. 2012. Differential expression of nitrate reductase in response to potassium and sodium nitrate: realtime PCR analysis. Austr. J. Crop Sci. 6:130-134.

Below, F.E., Cazetta, J.O., Seebauer, J.R. 2000. Carbon/nitrogen interactions during ear and kernel development of maize, In: Westgate, M., Boote, K. (eds), Physiology and Modelling Kernel set in Maize. CSA Special Publication no. 29. CSSA-ASA. Madison, WI, USA. pp. 15-24.

Bijlsma, R.J., Lambers, H., Kooijman, S.A.L.M. 2000. A dynamic whole plant model of integrated metabolism of nitrogen and carbon. 1. Comparative ecological implications of ammonium-nitrate interactions. Plant Soil 220:49-69.

Britto, D.T., Kronzucker, H.J. 2002. Review NH4+ toxicity in higher plants: a critical review. J. Plant Physiol. 159:567-584.

Bulen, W.A. 1956. The isolation and characterization of glutamate dehydrogenase from corm leaves. Archives of Biochemistry and Biophysics 62:178-183.

Christeller, J.T., Laing, W.A., Sutton, W.D. 1977. Carbon dioxide fixation by lupin root nodules. I. Characterization, association with phosphoenolpyruvate carboxylase, and correlation with nitrogen fixation during nodule development. Plant Physiol. 60:47-50.

Cossey, D.A., Thomason, W.E., Mullen, R.W., Wynn, K.J., Woolfolk, C.W., Johnson, G.V., Raun, W.R. 2002. Relationship between ammonium and nitrate in wheat plant tissue and estimated nitrogen loss. J. Plant Nutrition 25:1429-1442.

Cruz, C., Bio, A.F.M., Dominguez-Valdivia, M.D., Aparicio-Tejo, P.M., Lamsfus, C., Martins-Loucao, M.A. 2006. How does glutamine synthetase activity determine plant tolerance to ammonium? Planta 223:10681080 .

Dubois, M., Gilles, K.A., Hamilton, J.K., Rebers, P.A., Smith, F. 1956. Colorimetric method for determination of sugars and related substances. Anal. Chem. 28:350-356.

Fathi, G. 2008. Effect of genotype variability on nitrate uptake and assimilation of wheat cultivars. J. of Agric. Sci. and Technol. 10:11-22.

Gietl, C. 1992. MDH isoenzymes: Cellular localization and role in the flow of metabolites between the cytoplasm and cell organelles. Biochimica et Biophysica Acta 1100:217-234.

Hawkesford, M.J. 2014. Reducing the reliance on nitrogen fertilizer for wheat production. J. Cereal Sci. 59:276-283. 
Hoagland, D.R., Arnon, D.I. 1950. The water-culture method for growing plants without soil. California Agricultural Experiment Station Publication 347:1-32.

Hodges, M. 2002. Enzyme redundancy and the importance of 2-oxoglutarate in plant ammonium assimilation. J. Exp. Bot. 53:905-916.

Huppe, H., Turpin. D.H. 1994. Integration of carbon and nitrogen metabolism in plant and alga cells. Annu. Rev. Plant Physiol. and Plant Mol. Biol. 45:577-607.

Ikram, S., Bedu, M., Daniel-Vedele, F., Chaillou, S., Chardon, F. 2012. Natural variation of Arabidopsis response to nitrogen availability. J. Exp. Bot. 63:91-105.

Jain, V., Khetarpal, S., Das, R., Abrol, Y.P. 2011. Nitrate assimilation in contrasting wheat genotypes. Physiol. and Mol. Biol. of Plants 17:137-144.

Jaworski, E.G. 1971. Nitrate reductase in intact plant tissue. Biochem. and Biophysic. Res. Commun. 43:12741279.

Jiang, D., Cao, W.X., Dai, T.B., Jing, Q. 2003. Activities of key enzymes for starch synthesis in relation to growth of superior and inferior grains on winter wheat (Triticum aestivum L.) spike. Plant Growth Regul. 41:247-257.

Kanamori, T., Matsumoto, H. 1974. Asparagine synthesis by Oryza sativa seedlings. Phytochem. 13:14071412.

Lancien, M., Gadal, P., Hodges, M. 2000. Enzyme redundancy and the importance of 2-oxoglutarate in higher plant ammonium assimilation. Plant Physiol. 123:817-824.

Lancien, M., Martin, M., Hsieh, M-H., Leustek, T., Goodman, H., Coruzzi, G.M. 2002. Arabidopsis glt1-T mutant defines a role for NADH-GOGAT in the non-photorespiratory ammonium assimilatory pathway. The Plant J. 29:347-358.

Lasa, B., Frechilla, S., Aparicio-Tejo, P.M., Lamsfus, C. 2002. Role of glutamate dehydrogenase and phosphoenolpyruvate carboxylase activity in ammonium nutrition tolerance in roots. Plant Physiol. and Biochem. 40:969-976.

Lea, D.J., Robinson, S.A., Steward, G.R. 1990. The enzymology and metabolism of glutamine, glutamate and asparagines. In: Miflin, B.J., Lea, P.J. (eds), The Biochemistry of Plants, Vol. 16. Academics Press. New York, USA. pp. 121-159.

Lee, Y.P., Takahashi, T. 1966. An improved colorimetric determination of amino acid with the use of ninhydrin. Anal. Biochem. 14:71-77.

Lewis, O.A.M., Fulton, B., von Zelewski, A.A.A. 1987. The differential distribution of carbon in response to nitrate, ammonium and nitrate-ammonium nutrition in wheat. In: Ullrich, W.R., Aparcio, P.J., Syrett, P.J., Castillo, F. (eds), Inorganic Nitrogen Metabolism. Springer Verlag. Berlin, Germany. pp. 240-246.

Lin, C.C., Kao, C.H. 2001. Regulation of ammonium-induced proline accumulation in detached rice leaves. Plant Growth Regul. 35:69-74.

Lowry, O.H., Rosenbrough, N.J., Farr, A.L., Randall, R.J. 1951. Protein measurement with folin phenol reagent. J. Biol. Chem. 193:265-275.

Luo, J., Sun, S., Jia, L., Chen, W., Shen, Q. 2006. The mechanism of nitrate accumulation in pakchoi [Brassica campestris L. ssp. Chinensis (L.)]. Plant Soil 282:291-300.

Masclaux-Daubresse, C., Daniel-Vedele, F., Dechorgnat, J., Chardon, F., Gaufichon, L., Suzuki, A. 2010. Nitrogen uptake, assimilation and remobilization in plants: challenges for sustainable and productive agriculture. Ann. Bot. 105:1141-1157.

Masclaux-Daubresse, C., Reisdorf-Cren, M., Pageau, K., Lelandais, M.A., Grandjean, O., Kronenberger, J., Valadier, M.-H., Feraud, M., Jouglet, T., Suzuki, A. 2006. Glutamine synthetase-glutamate synthase pathway and glutamate dehydrogenase play distinct roles in the sink-source nitrogen cycle in tobacco. Plant Physiol. 140:444-456.

McKenzie, H.A., Wallace, H.S. 1954. The Kjeldahl determination of nitrogen. Austr. J. Chem. 17:55-59.

Miflin, B.J., Lea, P.J. 1976. The pathway of nitrogen assimilation in plants. Phytochem. 15:873-885.

Miyao, M., Fukayama, H. 2003. Metabolic consequences of overproduction of phosphoenolpyruvate carboxylase in $C_{3}$ plants. Archives of Biochemistry and Biophysics 414:197-203.

Mohanty, B., Fletcher, J.S. 1980. Ammonium influence on nitrogen assimilatory enzymes and protein accumulation in suspension cultures of pearl scarlet rose. Physiologia Plantarum 48:453-459. 
Morell, M., Copeland, L. 1985. Sucrose synthase of soybean nodules. Plant Physiol. 78:149-154.

Morozkina, E.V., Zvyagilskaya, R.A. 2007. Nitrate reductases: Structure, functions and effect of stress factors. Biochem. 72:1151-1160.

Nasholm, T., Kielland, K., Ganeteg, U. 2009. Uptake of organic nitrogen by plants. New Phytologist 182:3148.

Nunes-Nesi, A., Fernie, A.R., Stitt, M. 2010. Metabolic and signaling aspects underpinning the regulation of plant carbon nitrogen interactions. Mol. Plant 3:973-996.

Osuji, G.O., Brown, T.K., South, S.M. 2009. Nucleotide-dependent reprogramming of mRNAs encoding acetyl coenzyme A carboxylase and lipoxygenase in relation to the fat contents of peanut. J. Bot. 10:1-8.

Pasqualini, S., Ederli, L., Piccioni, C., Batini, P., Bellucci, M., Arcioni, S., Antonielli, M. 2001. Metabolic regulation and gene expression of root phosphoenolpyruvate carboxylase by different nitrogen sources. Plant Cell Environ. 24:439-447.

Patterson, K., Cakmak, T., Cooper, A., Lager, I., Rasmusson, A.G., Escobar, M.A. 2010. Distinct signaling pathways and transcriptome response signatures differentiate ammonium- and nitrate-supplied plants. Plant Cell Environ. 33:1486-1501.

Raab, T.K., Terry, N. 1994. Nitrogen source regulation of growth and photosynthesis in Beta vulgaris L. Plant Physiol. 105:1159-1166.

Rad, J.S., Rad, M.S., Miri, A. 2013. Regulation of the expression of nitrate reductase genes in leaves of medical plant, Foeniculum vulgare by different nitrate sources. Int. J. of Agric. and Crop Sci. 5:2911-2916.

Roosta, H.R., Sajjadinia, A., Rahimi, A., Schrjoerring, J.K. 2009. Responses of cucumber plant to $\mathrm{NH}_{4}^{+}$and $\mathrm{NO}_{3}^{-}$nutrition: the relative addition rate technique vs. cultivation at constant nitrogen concentration. Scientia Horticulturae 121:397-403.

Sadras, V.O., Lawson, C. 2013. Nitrogen and water-use efficiency of Australian wheat varieties released between 1958 and 2007. Eur. J. Agron. 46:34-41.

Schluter, U., Mascher, M., Colmsee, C., Scholz, U., Brautigam, A., Fahnenstich, H., Sonnewald, U. 2012. Maize source leaf adaptation to nitrogen deficiency affects not only nitrogen and carbon metabolism but also control of phosphate homeostasis. Plant Physiol. 160:1384-1406.

Singh, R., Perez, C.M., Pascual, C.G., Juliano, B.O. 1978. Grain size, sucrose level and starch accumulation in developing rice grain. Phytochem. 17:1869-1874.

Singh, R., Asthir, B.1988. Import of sucrose and its transformation to starch in the developing sorghum caryopsis. Physiologica Plantarum 74:58-65.

Stommel, J.R. 1992. Enzymic components of sucrose accumulation in the wild tomato species Lycopersicon peruvianum. Plant Physiol. 99:324-328.

Tercé-Laforgue, T., Dubois, F., Ferrario-Mery, S., Pou de Crecenzo, M.A., Sangwan, R., Hirel, B. 2004. Glutamate dehydrogenase of tobacco (Nicotiana tabacum L.) is mainly induced in the cytosol of phloem companion cells when ammonia is provided either externally or released during photorespiration. Plant Physiol. 136:4308-4317.

Tezuka, T., Yamamoto, Y., Kondo, N. 1990. Activation of $\mathrm{O}_{2}$ uptake and NAD-specific isocitrate dehydrogenase in mitochondria isolated from cotyledons of castor bean by cis,trans-abscisic acid. Plant Physiol. 92:147-150.

Tonhazy, N.E. 1960a. Glutamate-oxaloacetate-transaminase. In: Bergmeyer, H.U. (ed.), Methods of Enzyme Analysis. Akademie-Verlag, Berlin, Germany. pp. 665-698.

Tonhazy, N.E. 1960b. Glutamate-pyruvate-transaminase. In: Bergmeyer, H.U. (ed.), Methods of Enzyme Analysis. Akademie-Verlag, Berlin, Germany. pp. 727-731.

Vance, C.P., Stade, S. 1984. Alfalfa root nodule carbon dioxide fixation. II. Partial purification and characterization of root nodule phosphoenolpyruvate carboxylase. Plant Physiol. 75:261-264.

Wojciechowski, T., Gooding, M.J., Ramsay, L., Gregory, P.J. 2009. The effects of dwarfing genes on seedling root growth of wheat. J. Exp. Bot. 60:2565-2573. 


\section{Electronic Supplementary Material (ESM)}

Electronic Supplementary Material (ESM) associated with this article can be found at the website of CRC at http://www.akademiai.com/content/120427/

Electronic Supplementary Table S1. Effect of different nitrogen source on growth parameters of hydroponically grown two wheat genotypes (PBW 343 and GLU 1356)

Electronic Supplementary Table S2. Correlation coefficients between carbon and nitrogen metabolism at different nitrogen source in shoot and root of hydroponically grown two wheat genotypes (PBW 343 and GLU 1356)

Electronic Supplementary Figure S1. Effect of different nitrogen source on nitrate reductase (NR, $\mu$ mol $\mathrm{NO}_{2}^{-}$ released/h/g FW), glutamine synthetase (GS, $\mu \mathrm{mol} \mathrm{NADH} \mathrm{oxidized/min/g} \mathrm{FW),} \mathrm{glutamate} \mathrm{synthase} \mathrm{(GOGAT,}$ $\mu \mathrm{mol} \mathrm{NADH}$ oxidized/min/g FW), glutamate dehydrogenase (GDH, $\mu \mathrm{mol} \mathrm{NADH} \mathrm{oxidized/min/g} \mathrm{FW),} \mathrm{gluta-}$ mate oxaloacetate transaminase (GOT, $\mu$ mol oxaloacetate $\min ^{-1} \mathrm{~g}^{-1} \mathrm{FW}$ ) and glutamate pyruvate transaminase (GPT, $\mu$ molpyruvate $\mathrm{min}^{-1} \mathrm{~g}^{-1} \mathrm{FW}$ ) in shoot and root of hydroponically grown two wheat genotypes (PBW 343 and GLU 1356). A - Genotypes, B - Treatments, AB - Genotypes $\times$ Treatments

Electronic Supplementary Figure S2. Effect of different nitrogen source on sucrose synthase (SS, $\mu$ mol sucrose $\mathrm{min}^{-1} \mathrm{mg}^{-1}$ protein), soluble acid invertase (AI, $\mu \mathrm{mol}$ sucrose $\mathrm{min}^{-1} \mathrm{mg}^{-1}$ protein), soluble neutral invertase (NI, $\mu \mathrm{mol}$ sucrose $\mathrm{min}^{-1} \mathrm{mg}^{-1}$ protein), phosphoenolpyruvate carboxylase (PEPC, $\mu$ mol NADH oxidized $\mathrm{g}^{-1}$ $\mathrm{FW} \mathrm{min}^{-1}$ ), isocitrate dehydrogenase (ICDH, $\mu \mathrm{mol}$ NADP reduced $\mathrm{g}^{-1} \mathrm{FW} \mathrm{min}^{-1}$ ) and malatedehydrogenase (MDH, NADH oxidized $\mathrm{g}^{-1} \mathrm{FW} \mathrm{min}^{-1}$ ) in shoot and root of hydroponically grown two wheat genotypes (PBW 343 and GLU 1356). A - Genotypes, B - Treatments, AB - Genotypes $\times$ Treatments

Electronic Supplementary Figure S3. Effect of different nitrogen source on total soluble protein (mg/g DW), amino acid (mg/g DW), nitrogen (\%) and total free sugars $(\mathrm{mg} / \mathrm{g})$ content in shoot and root of hydroponically grown two wheat genotypes (PBW 343 and GLU 1356). A - Genotypes, B - Treatments, AB Genotypes $\times$ Treatments 